\title{
A Counselling Model for BRCA1/2 Genetic Susceptibility Testing
}

\author{
Iris van Oostrom', Aad Tibben ${ }^{2}$ \\ 'Department of Clinical Genetics, Department of Medical Psychology and Psychotherapy, Erasmus MC, Rotterdam, the Netherlands; ${ }^{2}$ Centre of Human and Clinical Genetics, \\ Leiden University Medical Centre, Leiden, the Netherlands
}

Key words: genetic testing, BRCA1, BRCA2, adverse psychological reactions, counselling protocol

Corresponding author: Iris van Oostrom, Department of Medical Psychology and Psychotherapy, Erasmus MC, P.0. box 1738, 3000 DR Rotterdam, the Netherlands; e-mail: i.vanoostrom@erasmusmc.nl

Submitted: 3 February 2004

Accepted: 20 February 2004

\begin{abstract}
When BRCA1/2 genetic susceptibility testing was introduced in the clinic in the mid-nineties, the "Huntington protocol" was used in the counselling of individuals applying for genetic testing. This protocol includes at least three sessions with a certain reflection period before blood sampling. Evidence on the psychological impact of BRCA1/2 genetic susceptibility testing has been accumulating in the last years. We will give a short overview of these psychological studies in order to reflect the need of using the extensive Huntington protocol in the counselling of individuals applying for BRCA $1 / 2$ genetic susceptibility testing. A shortened and more flexible $B R C A T / 2$ counselling protocol is delineated, in which the attention is focused on the needs and strengths of the individual.
\end{abstract}

\section{Introduction}

When genetic susceptibility testing for hereditary breast and/or ovarian cancer was introduced in the nineties, professionals were concerned about the psychological consequences of learning one's genetic status. Women carrying a BRCA $/ 2$ mutation have to deal with considerable health risks [1-3] and are confronted with difficult choices concerning risk management. Mutation carriers can opt for regular surveillance, for prophylactic mastectomy and/or prophylactic bilateral salpingo oophorectomy, and/or for chemoprevention trials. Besides important health risks and the far-reaching impact of risk management options, these women may be psychologically vulnerable due to unresolved loss experiences [4, 5]. Many have witnessed the disease in relatives and have lost a mother or sister, possibly leaving young children behind. Furthermore mutation carriers risk to pass or to have passed the mutation onto their children with all the above-mentioned consequences for them.

\section{The Huntington protocol}

Because of the potentially far-reaching implications of BRCAT/2 susceptibility testing, the "Huntington protocol" was adopted for the counselling of unaffected individuals who wanted to know whether they had inherited a familial BRCA1/2 mutation. This "Huntington protocol" has a long history. As the availability of DNA analysis for the HD gene was set to become a reality, the Committee of International Huntington Association and the Working Group on Huntington's disease of the World Federation of Neurology gave consideration to the manner in which these tests should be carried out (IHA/WFN 1994). In general, the guidelines recommend that individuals at risk who participate in predictive testing programmes are seen for two to four counselling 
Table 1. Predictive testing for Huntington's disease

Session one
- Sociodemographic details
- Confirmation of family and clinical data
- Assessment of impact of HD and test results
- Assessment of knowledge of HD and presymptomatic testing
- Reasons for requesting prediction
- Neurological examination*

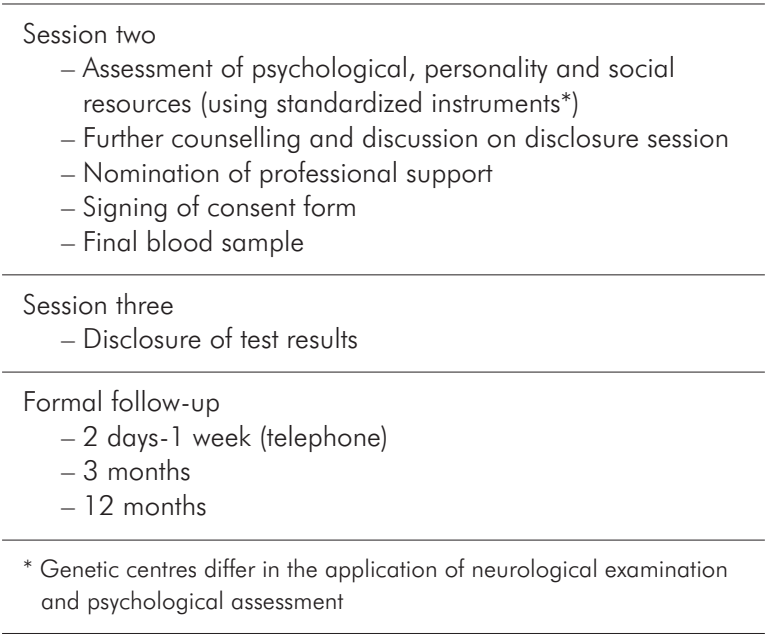

sessions, spread over a 3-month period, before disclosure of the test results. Predictive testing requires informed consent by the individual at risk, and the provision of psychological support. If the test is abnormal, counselling must be available for the family and others involved. The starting point is that predictive tests should be offered only to individuals at risk who have had the appropriate counselling, are fully informed, and wish to proceed. Genetic centres providing the predictive test have been committed to the use of the international guidelines. Admittedly, after 15 years, testing centres have developed their own local protocols and guidelines, based on experience and local or national rules, but what they have in common is the requirement for multiple interviews before a test result is disclosed. The number and complexity varies, partly due to the number of associated psychological and other evaluations, but the basic structure involves at least the series shown in Table 1.

The expectation of an increase of test requests for a great variety of hereditary disorders in the near future leads us to reconsider the need for such an extensive, time-consuming protocol in the counselling of individuals at risk, including those who may carry a familial BRCA $1 / 2$ mutation. What have the lessons of clinical experience and research provided so far?

\section{The psychological impact of genetic testing Need for help?}

Several psychological studies have now been conducted to determine the psychological impact of genetic susceptibility testing for BRCA1/2. In most studies groups of tested individuals were followed prospectively. Generally, the assessment took place before result disclosure and several weeks or months after result disclosure. Results from these studies suggest that participants generally cope well with genetic susceptibility testing. Non-mutation carriers reported a decline in psychological distress several weeks and months after result disclosure. Mutation carriers showed a stable or decreasing level of distress shortly after result disclosure [6-8] and up to 12 months after result disclosure [9-11]. Five years after result disclosure the level of distress increased again in both mutation carriers and non-mutation carriers [12]. On the whole the mean level of psychological distress remained underneath the clinical threshold, indicating little need for intervention [6-12]. In women affected by cancer also no adverse psychological reactions have been observed following genetic testing. They reported a decrease in anxiety and no change in depression rates one month after result disclosure [13]. Remarkably, the prospect of undergoing genetic testing was rated as less distressing than the high risk status or the diagnosis of cancer by women at risk and women with a personal and familial history of breast and/or ovarian cancer [14].

The occurrence of mental health problems was low. No unusually high levels of psychiatric disorder were detected in a group of 315 unaffected individuals from families with a known mutation of BRCA $1 / 2$ [15]. In another study [16] it was concluded that of 211 women with a previous history of breast and/or ovarian cancer and 253 unaffected women at risk remarkably few women reported psychological distress and met criteria for psychiatric disorder like depression, anxiety disorder, or alcohol abuse. Compared to women from primary care and community settings, they had lower rates of psychiatric disorder.

In summary, no elevated distress levels and a low prevalence of mental health problems have been observed both before and after BRCAl/2 genetic susceptibility testing. The participants of the studies described here wanted to know their genetic risk status and may therefore consist of a self-selected and psychologically stable subgroup of at risk individuals. Despite the psychological stability of the majority of the group, we emphasise that a subset of women undergoing genetic susceptibility testing for BRCA $1 / 2$ reports a level of distress that warrants clinical attention.

The request for psychological support proved to be rare in the short term [8]. Counselees who were 
referred for psychosocial help generally had more problems with issues like loss and family or partner relationships than with the concern of developing breast cancer [17]. In the five years following testing about half of the mutation carriers and a third of the non-carriers were found to have asked for professional support for psychological problems [12].

Several efforts have been made to identify counselees who risk suffering from psychological adverse reactions. An important precursor is pre-test psychological distress. Women reporting more psychological distress at the time of blood sampling generally continue to report higher distress levels after receiving the result $[7,8]$. In the main these women are younger $[5,15,18]$ and interested in prophylactic surgery [5].

Another factor was having an intimate relationship. Unmarried women seeking genetic counselling for a family history of breast/ovarian cancer reported more distress than married women in one study [18]. However another study [19] found equal levels of distress in married and unmarried women, but more distress in women with unhappy marriages. A study by Wylie et al [20] evaluated the effects of the support and distress of spouses on BRCAl/2 mutation carriers. Carriers who perceived their spouse to be anxious and non-supportive had higher distress levels one week after result disclosure than carriers who perceived their spouse to be supportive and anxious or low anxious and non-supportive. Carriers who perceived their spouse to be both supportive and low anxious had the lowest distress levels. In carriers with a non-supportive, anxious spouse at the time of testing, distress remained elevated up to two years after testing. The familial context may also be of importance. BRCAl/2 mutation carriers who were the first to be tested experienced more distress [21]. Non-carrier men reported more distress when they had carrier siblings and carrier women reported more distress when tested siblings had mixed results.

Several other studies have concentrated on coping, like the anticipation of the feelings following a positive result. Women who underestimated their feelings of distress following a positive test result, reported more psychological distress six months after having received the result [22]. A monitoring coping style, i.e. being very vigilant to threatening information, resulted in more psychological distress while waiting for the genetic test result [23], but not after receiving results [1 1, 23].

Decliners of genetic testing may also be more vulnerable to psychological distress. Women with high levels of baseline distress who declined genetic testing reported an important increase in depression rates [24]. Another study however did not find any psychological vulnerability in a (small) clinical sample of women at risk who did not opt for genetic testing [25].
Table 2. Genetic susceptibility testing for BRCAl/2

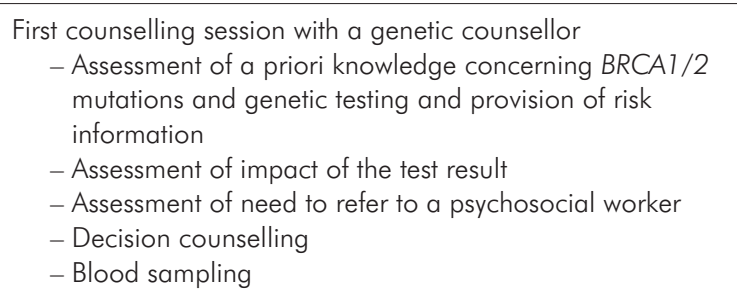

No blood sampling but a second counselling session with a genetic counsellor or psychosocial worker if:

- counselee experiences provided information as very unfamiliar or shocking or decision making was not thorough - other 'unfinished business' comes up such as relational conflicts, communication problems with relatives, worries about (future) children

- anticipation of inadequate coping with the test result

- the counselee is younger than 25

Disclosure session

- Disclosure of the test result by the genetic counsellor

- Assessment of need to refer to a psychosocial worker

- Referral to a specialist (for carriers)

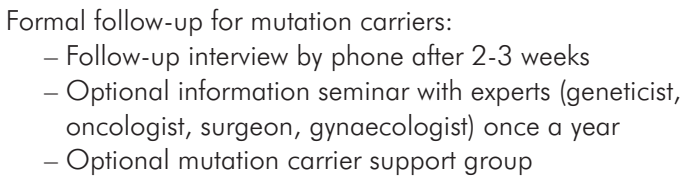

Formal follow-up for mutation carriers:

- Follow-up interview by phone after 2-3 weeks

- Optional information seminar with experts (geneticist, oncologist, surgeon, gynaecologist) once a year

- Optional mutation carrier support group

\section{A BRCA1/2 counselling protocol}

Genetic counselling should be tailored to the needs and capacities of its target group. If the target group generally has enough psychological resources to cope with genetic testing, our energy should be directed to the individuals who risk being unable to cope with it. Therefore we suggest adapting the Huntington protocol to the needs and strengths of our BRCAT/2 counselees. The shortened BRCAT/2 protocol we propose is depicted in Table 2. It comprises at least two sessions with a genetic counsellor and additional counselling suited to the needs of the counselee. This BRCA1/2 protocol could serve as a model for genetic susceptibility testing of other hereditary cancers such as HNPCC.

In the first session, careful exploration of the possible impact of testing upon the individual at risk and others involved enables the counselees and their partners to recognise the potential risk factors for inadequate coping. If there are any such factors, additional professional attention from a psychologist or social worker may be of help to anticipate untoward experiences after disclosure of test results. A second session with the counsellor can be offered when unanticipated information or facts emerge in the first session. This enables the counselee to reflect somewhat longer upon the possible consequences 
and to be more certain to make a thorough decision. Also after the session in which the test result is disclosed, follow-up support by a psychologist or social worker can be offered if needed. Otherwise a follow-up interview by phone and mentioning the possibilities of additional counselling may be sufficient. It is mandatory for the genetic counsellor to master specific communication skills and knowledge about the psychological risk factors, which enables him to identify those individuals who need additional support.

\section{Current practice and future research}

Several centres have already adopted a shortened protocol for counselees who apply for BRCA1/2 genetic susceptibility testing and in the United Kingdom certain centres have shortened the protocol for HNPCC pre-test counselling [26]. Aktan-Collan et al [27] evaluated a shortened protocol for predictive testing for HNPCC, that consisted of two sessions and no provision of additional psychological support. The majority (88\%) of counselees were satisfied with the procedure and suggested no changes. The counselees who suggested changes generally asked for more written material, not for more counselling sessions. However half of the counselees indicated that they might have used psychological support if it had been offered to them.

Given these results, we think it is unlikely that the proposed counselling protocol for BRCA $1 / 2$ genetic susceptibility testing results in an increase in adverse psychological reactions, but more research is necessary to evaluate which aspects of genetic counselling contribute to thorough decision making [28] and to the emotional well-being of counselees and their partners. Future research should also aim at determining the characteristics of individuals who might benefit from additional psychological support and at disentangling the psychological processes resulting in ineffective coping. This knowledge will enable us to identify these individuals as precisely as possible and to adjust our counselling further to the individual needs of the counselees.

\section{Acknowledgement}

The authors would like to thank Hanne MeijersHeijboer for her valuable feedback on the manuscript.

\section{References}

1. Easton DF, Ford D and Bishop DT. Breast and ovarian cancer incidence in BRCA1-mutation carriers. Breast Cancer Linkage Consortium. Am J Hum Genet 1995; 56 (1): 265-271.

2. Ford D, Easton DF, Stratton M, Narod S, Goldgar D, Devilee P, Bishop DT, Weber B, Lenoir G, Chang-Claude J, Sobol H, Teare
MD, Struewing J, Arason A, Scherneck S, Peto J, Rebbeck TR, Tonin P, Neuhausen S, Barkardottir R, Eyfjord J, Lynch H, Ponder BA, Gayther SA, Birch JM, Lindblom A, Stoppa-Lyonnet D, Bignon Y, Borg A, Hamann U, Haites N, Scott RJ, Maugard CM, Vasen H, Seitz S, Cannon-Albright LA, Schofield A and Zelada-Hedman M. Genetic heterogeneity and penetrance analysis of the BRCA1 and BRCA2 genes in breast cancer families. The Breast Cancer Linkage Consortium. Am J Hum Genet 1998; 62 (3): 676-689.

3. Antoniou A, Pharoah PD, Narod S, Risch HA, Eyfjord JE, Hopper $\mathrm{JL}$, Loman N, Olsson H, Johannsson $\mathrm{O}$, Borg A, Pasini B, Radice P, Manoukian S, Eccles DM, Tang N, Olah E, Anton-Culver H, Warner E, Lubinski J, Gronwald J, Gorski B, Tulinius H, Thorlacius S, Eerola H, Nevanlinna H, Syrjakoski K, Kallioniemi OP, Thompson D, Evans C, Peto J, Lalloo F, Evans DG and Easton DF. Average Risks of Breast and Ovarian Cancer Associated with BRCA1 or BRCA2 Mutations Detected in Case Series Unselected for Family History: A Combined Analysis of 22 Studies. Am J Hum Genet 2003; 72 (5): $1117-1130$.

4. Horowitz M, Sundin E, Zanko A and Lauer R. Coping with grim news from genetic tests. Psychosomatics 2001; 42 (2): 100-105.

5. Lodder LN, Frets PG, Trijsburg RW, Meijers-Heijboer EJ, Klijn JG, Duivenvoorden HJ, Tibben A, Wagner A, van der Meer CA, Devilee P, Cornelisse CJ and Niermeijer MF. Presymptomatic testing for BRCA1 and BRCA2: how distressing are the pre-test weeks? J Med Genet 1999; 36 (12): 906-913.

6. Lerman C, Narod S, Schulman K, Hughes C, Gomez-Caminero A, Bonney G, Gold K, Trock B, Main D, Lynch J, Fulmore C, Snyder C, Lemon SJ, Conway T, Tonin P, Lenoir G and Lynch H. BRCA1 testing in families with hereditary breast-ovarian cancer. A prospective study of patient decision making and outcomes. JAMA 1996; 275: 1885-1892.

7. Croyle RT, Smith KR, Botkin JR, Baty B and Nash J. Psychological response to BRCA1 mutation testing: preliminary findings. Health Psychol 1997; 16: 63-72.

8. Lodder L, Frets PG, Trijsburg RW, Meijers-Heijboer EJ, Klijn JG, Duivenvoorden HJ, Tibben A, Wagner A, van der Meer CA, van den Ouweland AM and Niermeijer MF. Psychological impact of receiving a BRCA1/BRCA2 test result. Am J Med Genet 2001; 98: 15-24.

9. Schwartz MD, Peshkin BN, Hughes C, Main D, Isaacs C and Lerman C. Impact of BRCA1/BRCA2 mutation testing on psychologic distress in a clinic-based sample. J Clin Oncol 2002; 20 (2): 514-520.

10. Lodder LN, Frets PG, Trijsburg RW, Meijers-Heijboer EJ, Klijn JG, Seynaeve C, van Geel AN, Tilanus MM, Bartels CC, Verhoog LC, Brekelmans CT, Burger CW and Niermeijer MF. One year follow-up of women opting for presymptomatic testing for BRCA1 and BRCA2: emotional impact of the test outcome and decisions on risk management (surveillance or prophylactic surgery). Breast Cancer Res Treat 2002; 73 (2): 97-112.

11. Meiser B, Butow P, Friedlander M, Barratt A, Schnieden V, Watson $M$, Brown J and Tucker K. Psychological impact of genetic testing in women from high-risk breast cancer families. Eur J Cancer 2002; 38 (15): 2025-2031.

12. Van Oostrom I, Meijers-Heijboer H, Lodder LN, Duivenvoorden HJ, van Gool AR, Seynaeve C, van der Meer CA, Klijn JG, van Geel BN, Burger CW, Wladimiroff JW and Tibben A. Long-term psychological impact of carrying a BRCA1/2 mutation and prophylactic surgery: a 5-year follow-up study. J Clin Oncol 2003; 21 (20): 3867-3874.

13. Wood ME, Mullineaux L, Rahm AK, Fairclough D and Wenzel L. Impact of BRCA1 testing on women with cancer: a pilot study. Genet Test 2000; 4 (3): 265-272. 
14. Coyne JC, Kruus L, Racioppo M, Calzone KA and Armstrong K. What do ratings of cancer-specific distress mean among women at high risk of breast and ovarian cancer? Am J Med Genet 2003; 116 (3): 222-228.

15. Foster C, Evans DG, Eeles R, Eccles D, Ashley S, Brooks L, Davidson R, Mackay J, Morrison PJ and Watson M. Predictive testing for BRCA1/2: attributes, risk perception and management in a multi-centre clinical cohort. Br J Cancer 2002; 86 (8): 1209-1216.

16. Coyne JC, Benazon NR, Gaba CG, Calzone K and Weber BL. Distress and psychiatric morbidity among women from high-risk breast and ovarian cancer families. J Consult Clin Psychol 2000; 68: 864-874

17. Hopwood P, Keeling F, Long A, Pool C, Evans G and Howell A. Psychological support needs for women at high genetic risk of breast cancer: some preliminary indicators. Psychooncology 1998; 7 (5): 402-412.

18. Audrain J, Schwartz MD, Lerman C, Hughes C, Peshkin BN and Biesecker B. Psychological distress in women seeking genetic counselling for breast-ovarian cancer risk: the contributions of personality and appraisal. Ann Behav Med 1997; 19 (4): 370-377.

19. Coyne JC and Anderson KK. Marital status, marital satisfaction, and support processes among women at high risk for breast cancer. J Fam Psychol 1999; 13: 629-641.

20. Wylie JE, Smith KR and Botkin JR. Effects of spouses on distress experienced by BRCA1 mutation carriers over time. Am J Med Genet 2003; $119 \mathrm{C}(1)$ : 35-44

21. Smith KR, West JA, Croyle RT and Botkin JR. Familial context of genetic testing for cancer susceptibility: moderating effect of siblings' test results on psychological distress one to two weeks after BRCA1 mutation testing. Cancer Epidemiol Biomarkers Prev 1999; 8: 385-392.

22. Dorval M, Patenaude AF, Schneider KA, Kieffer SA, DiGianni L, Kalkbrenner KJ, Bromberg JI, Basili LA, Calzone K, Stopfer J, Weber BL and Garber JE. Anticipated versus actual emotional reactions to disclosure of results of genetic tests for cancer susceptibility: findings from $\mathrm{p} 53$ and BRCA1 testing programs. J Clin Oncol 2000; 18: 2135-2142.

23. Tercyak KP, Lerman C, Peshkin BN, Hughes C, Main D, Isaacs $C$ and Schwartz MD. Effects of coping style and BRCA1 and BRCA2 test results on anxiety among women participating in genetic counselling and testing for breast and ovarian cancer risk. Health Psychol 2001; 20 (3): 217-222.

24. Lerman C, Hughes C, Lemon SJ, Main D, Snyder C, Durham $C$, Narod S and Lynch HT. What you don't know can hurt you: adverse psychologic effects in members of BRCA 1 -linked and BRCA2-linked families who decline genetic testing. J Clin Oncol 1998; 16: 1650-1654.

25. Lodder L, Frets PG, Triisburg RW, Klijn JG, Seynaeve C, Tilanus MM, Bartels CC, Meijers-Heijboer EJ, Verhoog LC and Niermeijer MF. Attitudes and distress levels in women at risk to carry a BRCA1/BRCA2 gene mutation who decline genetic testing. Am J Med Genet 2003; 119A (3): 266-272.

26. Brain K, Soldan J, Sampson J and Gray J. Genetic counselling protocols for hereditary non-polyposis colorectal cancer: a survey of UK regional genetics centres. Clin Genet 2003; 63 (3): 198-204.

27. Aktan-Collan K, Mecklin JP, de la Chapelle A, Peltomaki P, Uutela $\mathrm{A}$ and Kaariainen $\mathrm{H}$. Evaluation of a counselling protocol for predictive genetic testing for hereditary non-polyposis colorectal cancer. J Med Genet 2000; 37 (2): 108-1 13.

28. Julian-Reynier C, Welkenhuysen M, Hagoel L, Decruyenaere M, Hopwood P; CRISCOM Working Group. Risk communication strategies: state of the art and effectiveness in the context of cancer genetic services. Eur J Hum Genet 2003; 11 (10): 725-736. 